\title{
Serigrafi Baskı Tekniğinde Kalıp Malzemesi Olarak Kullanılan Sentetik Dokumaların Baskı Kalitesi ve Kullanım Performansını Belirleyen Üretim Süreçlerinin Analizi
}

\author{
Engin $\mathrm{UĞUR}^{1 *}$ \\ ${ }^{1}$ İstanbul Üniversitesi Cerrahpaşa, Basım ve Yayın Teknolojileri Programı, Teknik Bilimler Meslek Yüksekokulu, İstanbul, Türkiye, (ORCID: 0000-0001-7831-5449)
}

(İlk Geliş Tarihi 3 Mart 2019 ve Kabul Tarihi 25 Mart 2019)

(DOI: 10.31590/ejosat.535006)

REFERENCE: Uğur, E. (2019). Serigrafi Baskı Tekniğinde Kalıp Malzemesi Olarak Kullanılan Sentetik Dokumaların Bask1 Kalitesi ve Kullanım Performansını Belirleyen Üretim Süreçlerinin Analizi. Avrupa Bilim ve Teknoloji Dergisi, (15), 526-534.

Öz

Serigrafi bask1 işleminde şablon görüntünün oluşturulduğu kalıp malzemesi tekstil ürünüdür. Bu tekstil ürünü önceleri doğal ipek dokuma iken sentetik ürünlerin geliştirilmesi ile yerini sentetik dokumalara bırakmıştır. Serigrafi baskı işleminde kullanmak üzere üretilen sentetik dokumalar, polyamid ve polyester hammaddeden üretilmektedirler. Polyamid (naylon) sentetik dokumalar tek lifli (monofilament) yapıya sahiptir. Polyester dokumalar çok lifli (multifilament) yapıya sahiptir. Fiziki yapıları ve ham madde özelliklerinden dolayı baskı kalitesi ve kullanım performansları farklılık göstermektedir.

Serigrafi baskı operatörünün bilmesi gereken genel olarak, baskı yapacağı işin özelliğine göre teklifli (polyamid) veya çok lifli(polyester) dokuma çeşitleri arasından en uygun dokuma sıkılığı ve iplik kalınlığına sahip dokumayı seçmektir. Fakat seçtiği dokumanın iplik yapısından veya dokuma işleminden kaynaklanan problemler hem baskı sonucunu etkiler hem de teknik ve ekonomik açıdan kayıpların oluşmasına neden olabilmektedir.

Matbaacılık ülkemizde tüm baskı teknikleri ile çok büyük bir sektörel yapıya dönüşmüştür. Bu yapıda özellikle büyük işletmeler kalite konusunda çok hassasiyet göstermektedirler. Baskı kalitesinde sürekliliği sağlamak için tüm unsurlara hâkim olmaya çalışılmaktadırlar. Baskı işleminde kullanılan girdilerin kaynağına ulaşılarak problemlere kalıcı çözümler bulunmaya çalışılmaktadır. Bu çerçevede sentetik dokumaların üretimini yapan işletmelerle ortak hareket edilme yoluna gidilmektedir. Ortak hareket ederek çözüm üretmede temel unsur karşılıklı bilgi alışverişinden geçmektedir. Matbaa tarafı performansı ve problemleri çok iyi tanımlamalı ki dokuma üreticisi de buna göre üretim yapısını yapılandırsın. Makalenin bu perspektiften değerlendirilmesi gerekmektedir. Makalede sentetik dokumaların baskı kalitesi ve kullanım performansında etkili olan üretim unsurları tanımlanarak sebep sonuç ilişkisi kurulmaya çalışılmıştır.

Anahtar Kelimeler: Serigrafi baskı, Sentetik dokuma, Baskı kalitesi, Performans, Dokuma üretimi

\section{Analysis of Production Processes Determining Print Quality and Usage Performance of Synthetic Fabrics Used as Mesh Materials in Screen Printing Technique}

\begin{abstract}
${ }^{1}$ Sorumlu Yazar: İstanbul Üniversitesi Cerrahpaşa, Basım ve Yayın Teknolojileri Programı, Teknik Bilimler Meslek Yüksekokulu, İstanbul, TÜRKIYE ORCID: 0000-0001-7831-5449, engines@istanbul.edu.tr
\end{abstract}


The screen material in which the stencil image is formed in the screen printing process is the textile product. This textile product was previously woven from natural silk while it was replaced by synthetic fabrics by the development of synthetic products. Synthetic fabrics, which are produced for use in screen printing, are made of polyamide and polyester raw material. Polyamide (nylon) synthetic fabrics have a monofilament structure. Polyester fabrics have a multifilament structure. Due to their physical structure and raw material properties, print quality and usage performances differ.

In general, the screen printing operator needs to know, depending on the nature of the job to be printed (polyamide) or multi-fiber (polyester) is the most appropriate weaving types and weaving weights to choose the weaving thickness of the yarn. However, the problems caused by the yarn structure or weaving process of the selected fabric can affect the printing result and cause the loss of technical and economic losses.

Printing has turned into a very big sectoral structure in our country with all printing techniques. In this structure, large enterprises are very sensitive about quality. In order to ensure continuity in print quality, all elements are tried to dominate. It is tried to find permanent solutions to the problems by reaching the source of the inputs used in the printing process. In this context, it is possible to cooperate with the enterprises that produce the synthetic fabrics. The main element in producing solutions is to exchange information. The printingside performance and the problems should be well defined, so that the fabric manufacturer can also construct the production structure accordingly. The article should be evaluated from this perspective. In the article, it is tried to establish cause-effect relationship by defining the production elements which are effective on print quality and usage performance of synthetic fabrics.

Keywords: Screenprinting, Synthetic weaving, Print quality, Performance, Weaving production

\section{Giriş}

Serigrafi baskı işleminde petrol alt ürünü olan sentetik dokumalardan önce doğal ipek dokuma kullanılmıştır. Sentetik ürünler yaygınlık kazanmaya başlayınca doğal ipek dokuma yerini sentetik dokumalara bırakmıştır. Sentetik dokumaların, sahip oldukları özellikler baskı kalitesi ve kullanım performansı açısından doğal ürünlerden açık ara üstünlük sağlamıştır. Fakat her geçen gün yeni piyasaya çıkan spesifik bir baskı altı malzemeye baskı yapmak gerektiğinde beklenmedik sonuçlarla karşılaşılabilmektedir. Günümüzün baskı malzemesi ve teknolojisi çeşitliliği, ihtisaslaşmış ürünler kullanılmasını zorunlu kılmaktadır. Ortaya çıkan değiş̧ime ve yenliğe ayak uydurabilmek için özellikle baskı sonucunu direkt etkileyen girdilerin üretim aşamasından başlayarak son aşamaya kadar kontrol altında tutulmasını gerektirmektedir. Bu nedenle serigrafi baskı bilgisi kadar kimya, yada mekanik yada elektrik bilgisi gerekebilmektedir.

Serigrafi baskı işleminde baskı sonucuna hakim olmak için dokuma kalıbın hassas noktalarını bilmek ve buna göre hareket etmek büyük önem taşımaktadır. Üretimde kullanılan ham madde yapısı veya üretim işlemlerinden kaynaklanan bir durumun kullanım aşamasında düzelme imkanı çok zayıf bir ihtimal oluşturmaktadır. Önemli olan problem oluşturan konunun tespit edilip kaynağında çözülmesidir. Bu durum diğer tüm kullanıcılar içinde avantajlar sağlayacaktır.

\section{Serigrafi Baskı Tekniği}

Elek baskıda denilen serigrafi baskıda, çerçeveye gerilen ipek yada sentetik bir dokumanın üzerinde basılması istenmeyen yerler ışığa hassas emülsiyon ile kaplanır, filmle ile direkt bilgisayardan lazer ışıkla pozlandırılarak yada özel bir waksla inkjet sistemi ile basılması istenen görüntü kalıp yüzeyine geçirilir su ile açma işleminden sonra görüntülü yerler mürekkebi içerisinden geçirecek şekilde açık bırakılır. Elde edilen şablona mürekkep verilir ve bir rakle yardımı ile mürekkep şablon boyunca basınçla çekilir. Mürekkep emülsiyon ile kaplı olan bölgelerden geçemez, görüntünün olduğu bölgelerden ise ipeğin dokumaları arasından basılması istenen yüzeye geçerek baskı altı malzemesi üzerinde istenen görüntüyü oluşturur [1].

Baskı kalıbını hazırlamak için dokuma kalıp yüzeyine ışı̆ga duyarlı kimyasal madde sürülür, sürülen bu kimyasal maddenin temel özelliği 1ş̧ktan etkilenmesidir. Basılacak görüntünün 1şık geçirgenliği olan malzemedeki görüntüsünü kullanarak ışık kaynağı ile pozlandırılır. Pozlandırma işleminde ışık gören yerler ışık ışınlarının etkisi ile sertleşerek dokuma yüzeyinde tutunma özelliği kazanır. Işık görmeyen yerler de herhangi bir değişiklik olmaz. Daha sonra dokuma kalıp banyo işlemine tabi tutulur. Banyo işlemi, çeşme suyunun hortum ya da çok kuvvetli olmayan püskürtme cihazı yardımı ile kalıp yüzeyine birkaç dakika tutulması ile yapılır. Banyo işlemi sonucunda ışık görmeyen yerlerdeki kimyasal madde su yardımı ile dokuma yüzeyinden ayrılır, 1şık alan (pozlanan) yerler dokumanın yüzeyinde kalır. Baskı işlemi, mürekkebin sıyırgaç (rakle) yardımı ile dokuma kalıbın açık gözeneklerinden alta yer alan baskı materyaline transfer edilmesi ile gerçekleştirilir. Baskı işleminde mürekkep film katmanının kalitesinde çok çeşitli faktörler etki etmektedir. Bu faktörlerden biriside kalıp olarak kullanılan dokumadır.

Serigrafi baskı tekniği ile kumaş, plastik, cam, metal, ahşap malzemelere baskı yapılabilmektedir. Baskı imkanı çok geniş bir baskı tekniğidir. Fakat her malzemenin doku ve yüzey yapısına baskı işlemini yapmayı sağlayacak farklı özelliklere sahip ipek dokumalar, mürekkepler, yardımcı maddelerin kullanılması gerekmektedir. 


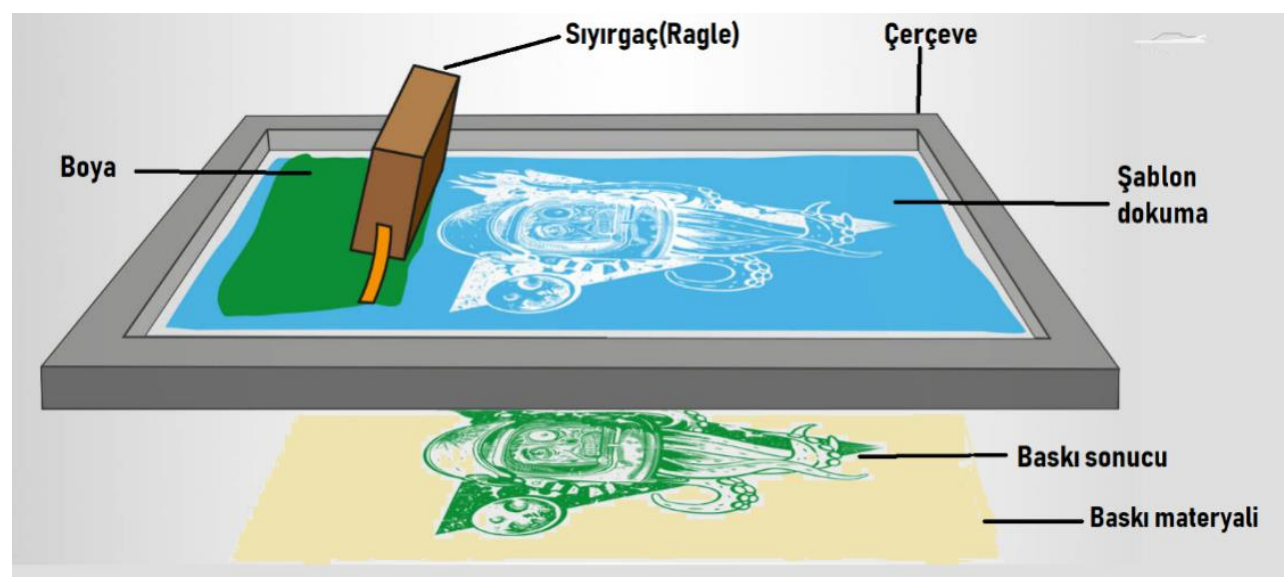

Şekil 1. Serigrafi baskı sistemi

\subsection{Sentetik Dokuma Nedir?}

Sentetik dokuma işleminde iplik olarak sentetik elyaf kullanılır. Elyaf, sentetik polimerlerden üretilir. Polimerler, çok sayıda küçük molekülün kovalent bağlarla birbirlerine bağlanarak oluşturduğu makromoleküllerdir[2]. Makro moleküller, monomerlerin kimyasal işlemler yoluyla bir araya gelerek uzun zincirler oluşturmasıdır. Bu işlem polimerizasyon olarak bilinmektedir [3]. Monomer adı verilen küçük moleküller uygun koşullarda polimerizasyon tepkimesi sonucu birbirleriyle kimyasal bağ yaparlar ve polimerleri oluştururlar. Polimerlerin üstün özellikleri üzerine makromoleküler yapılarının katkısı büyüktür[4]. Polimerik malzemelerin kullanım alanlarının fazla olmasının nedenleri sıralanırken hafifliği kolay işlenebilirliği ve mekanik özellikleri, belirtilmektedir[5].

\subsection{Serigrafi Baskı İşleminde Kalıp(Dokuma) Malzemesinde Olması Gereken Özellikler}

Dokuma, serigrafi baskı işleminde baskı sonucunu etkileyen önemli parametrelerdendir. Hazırlanan çalışmanın en küçük detayları ile firesiz kalıp olarak elde edilmesinde 1şı̆̆a duyarlı malzemenin kalitesi kadar dokumanın da istenen koşullarda olmasının önemi büyüktür. Baskı kalıbı olarak kullanılan sentetik dokumaların üretim teknik ve teknolojileri, hem baskı kalitesini hem de kullanım performansinı belirlemektedir.

Serigrafi baskı işleminde şablon haline getirilen dokuma malzemenin çerçeveye gerilmesi, kalıbın hazırlanması ve baskı işlemindeki kullanım işlemleri kullanıcıya ait olan kalite parametrelerini meydana getirmektedir. Bu parametreler, kullanıcının çalışmaya gösterdiği hassasiyet ve baskı öncesi ve baskı işleminde tercih ettiği malzeme ve teknolojilerle bağlantılıdır.

Baskı kalıp malzemesi olarak kullanılan dokuma, şablon kalıbı hazırlamak için kullanılan ışığa duyarlı malzeme (emülsiyon), baskı işleminde kullanılacak boya ve yardımcı malzemelerin performansları üretiminden kaynaklandığı için kullanıcının olumsuz kriterleri değiştirme imkanı bulunmamaktadır. Bu nedenle satın alma tercihini bilinçli yapmak gerekmektedir. Baskı kalıbı olarak kullanılan dokuma hem şablon görüntü oluşumunu hem de baskı işleminde boyanın baskı altı materyale transferini etkilemektedir.

Kalıp malzemesi olarak kullanılacak dokumanın baskı kalitesi açısından şu özelliklere sahip olması gerekmektedir;

1. Çerçeveye kolay gerilme ve gerginliği koruma

2. Işı̆̆a duyarlı malzemeyi (emülsiyon) dokuma liflerinde tutmak

3. Boyanın gözeneklerden kolay transfer edilmesini sağlamak

4. Baskı işleminde gerekli olan esnemeyi sağlamak

Serigrafi baskı işleminde çalışma performansı açısından şu özelliklere sahip olması gerekmektedir;

1. Çerçeveye kolay gerilebilmelidir

2. Baskı işleminde sürtünmeye karşı aşıma direnci yüksek olmalıdır

3. Boya ve 1 şı̆̆a duyarlı malzeme kolay temizlenmelidir

4. Boya ve kimyasal maddelere karşı dayanıklı olmalıdır

Baskı kalıbı olarak kullanılacak sentetik dokumaların yukarıda yer alan kriterleri sağlayacak özellikleri taşıması için üretiminin buna uygun yapılması gerekmektedir.

\subsection{Serigrafi Baskı İşleminde Kullanılan Sentetik Dokuma Türleri}

Polyamid (Naylon) İplik Dokumalar:

Poliamid (PA) lifleri, birçok endüstriyel alanda kullanılan önemli bir sentetik lif gurubudur. Sentetik dokuma olarak, PA 6.6 (naylon 6.6) ve PA 6 (naylon 6) yaygın olarak kullanılan poliamid lifleri arasında yer almaktadır. Polyamid lifleri 1sı, 1şık, ozon gibi atmosferik gazlar, kuvvetli asitler (nitrik asit, sülfirik asit vb.), yükseltgen maddeler (peroksitler vb), mikroorganizmalar ve bazı metallere karşı hassastirlar[6]. 


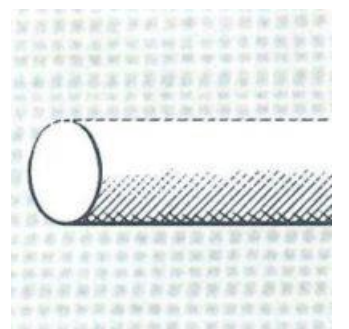

Şekil 2. Polyamid iplik kesiti

Poliester(Polyester) İplik Dokumalar:

Pamuktan sonra en çok kullanılan liftir ve hem üretim hem de tüketim açısından diğer sentetik liflerin çok ilerisindedir Poliester, polietilen teraftalat poliesteri olarak adlandırılır ve kısaca PET olarak ifade edilir. Poliester, çok aşamalı katalizör reaksiyonu kullanılarak oluşturulmaktadır[7].Genel olarak poliester lifleri, ağırlıkça en az \%85 oranında diol ve diasitin esterini içeren lifler olarak tanımlanmaktadır. Poliester ana zincirleri boyunca yinelenen ester bağları bulunmaktadır.Polyester lifin nem tutuculuğu sürekli ve kesikli liflerde \% 0,4'dür. Poliester lifleri, zayıf asitlere karșı asitlerin kaynama sıcaklıklarında dayanıklıdır. Kuvvetli asitlere oda sıcaklığında dayanımı iyi olmakla birlikte kuvvetli bazlar karşısında dayanımı zayıftır[2].

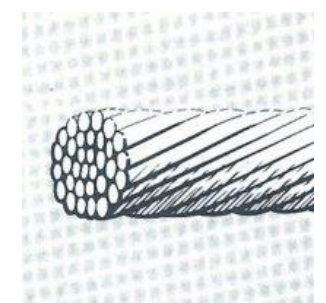

Şekil 3. Polyester iplik kesiti

\section{Sentetik Dokuma Üretimi}

Sentetik dokuma üretim prosesi; ham maddeyi meydana getiren polimerin elde edilmesi, dokuma lifi yada ipliğinin üretilmesi ve bu ipliğin dokunması aşamalarından meydana gelmektedir. Baskı kalitesi ve kulanım performansı, sentetik ham maddenin hazırlanmasından başlayarak ipliğin oluşturulması ve dokuma işleminin son aşamasına kadar yapılan işlemlerin sonucunda oluşmaktadır.

\subsection{Sentetik İplik Ham Maddesi Üretim İşlemi}

\subsubsection{Polyamid Ham Maddesi Üretimi}

Bunlardan PA 6.6, hekzametilendiamin ile adipik asidin polimerizasyonu sonucunda elde edilmektedir. PA 6 lifleri ise kaprolaktamdan elde edilmektedir. Sentez sırasında önce kaprolaktam halkası açılarak 6-amino hekzanoik aside dönüşmekte ve daha sonra bu amino asitin kendi kendine kondenzasyonu ile PA 6 polimeri elde edilmektedir[8].

Polyamid (Naylon)6.6 lifinin elde edilmesi için yapılacak ilk işlem bu iki maddenin uzun molekül zincirleri veya polimerler oluşturmasını sağlamaktır. Bu başlangıç maddeleri etil alkol içinde isıtıldığında naylon 6.6 tuzu oluşur. Bu tuzun sudaki çözeltisi basınç altında buhar verilerek havasız bir ortamda $215-220{ }^{\circ} \mathrm{C}$ 'de tutulduğunda polimerleşme başlar. Polimerizasyon derecesi istenilen seviyeye ulaştığında \% 1 oranında asetik asit eklenerek polimerizasyon durdurulur. Süt beyaz renkte olan ve katılaşan naylon 6.6 polimeri küçük parçalar şeklinde kesilir[9].

\subsubsection{Polyester Ham Maddesi Üretimi}

Polyester polimer maddesi, bir dialkol ile bir dikarboksilliasitin polimerizasyonu sonucu oluşur. Poliester lifleri ise; en az \%85 oranında dialkol ve tereftalik asit içeren uzun zincirli polimerlerden elde edilen lifler olarak tanımlanır[10]. Poliester lifleri tereftalik asit veya dimetil tereftalatın etilen glikol ile kondenzasyon reaksiyonu ile polimerizasyona uğraması sonucu elde edilir. Eğer polimerizasyonda asit olarak tereftalik asit kullanılırsa, polimerizasyon sonucu açığa su çıkar. Dimetil tereftalat kullanıldığı takdirde ise polimerizasyon sonucu açığa metil alkol çıkar [11].

\section{2. İplik Üretim İşlemi}

Eğer lif üretici firma polimer maddesini kendi üretiyorsa ve polimerizasyon üniteleri ile lif çekim üniteleri yan yana ise üretilen eriyik halindeki polimer doğrudan lif çekim ünitesine de beslenebilir. Aksi takdirde, katı granüller şeklinde olan polimer maddeyi eritip lif çekimine hazır hale getirmek için ekstruder denilen aparatlar ya da eski bir yöntem olan eritme ızgaraları kullanılır. Öncelikle katı polimer madde besleme tankına beslenir. Buradan lif çekim makinesinin ekstruderine iletilir ve bu bölümde eritilip basınçlandırılarak 
filtreye gönderilir. Filtre edilen polimer eriyiği manifoldlar aracıllı̆̆ ile lif çekim makinesinde bulunan düze kısmına gönderilir. Düze denilen aparatlar düze bloğu içerisinde yer alır[12].

Düze başlıkları, bir veya birden çok delik bulunan başlıklardır. Tek delikli düzeden tek lifli ‘monofilament’ lif (filament) çok delikli düzeden ise 'multifilament' çoklu lif (multifilament) elde edilir.

Ekstruderde eritilmiş polimer düzelere gelmeden önce mutlaka filtre edilmelidir. Filtre işleminin amacı, deliklerin tıkanmasını engellemektir. $\mathrm{Bu}$ amaçla eriyik içerisindeki katkı maddesi topakları, her türlü yabancı parçacık ve erimemiş polimer parçaları filtreler tarafından ayrılır. Bu sayede lif içerisinde bu kirliliklerin meydana getirebileceği düzgünsüzlükler ve hatalar da engellenmiş olur[13].

(a)

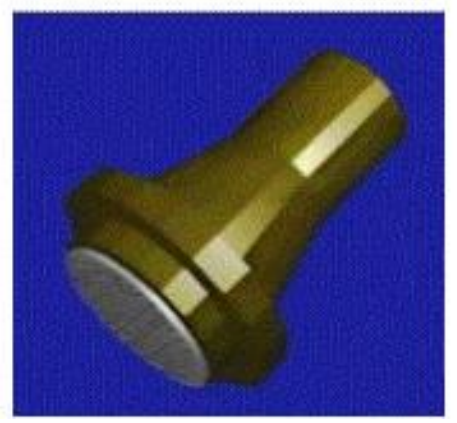

(b)

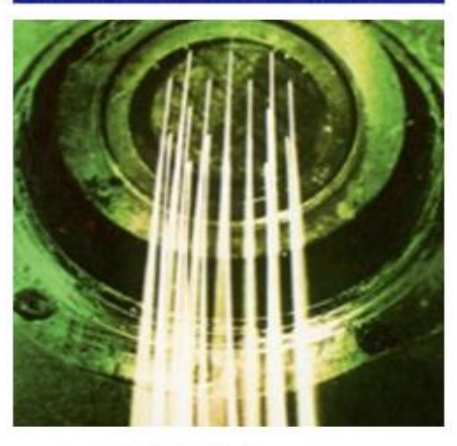

(c)

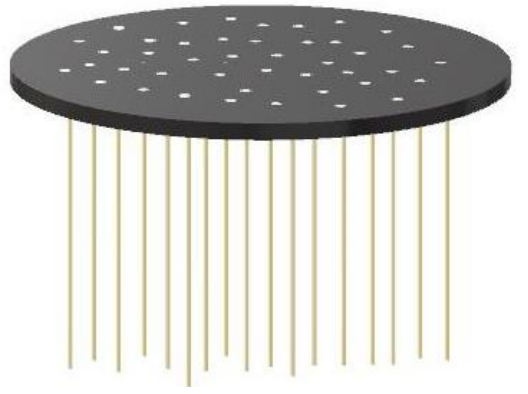

Şekil 4.(a) Düze(spinneret) başlığı, (b)Düzeden filament çıkışı ve (c)Düzenin çalışma sistemi

(a)

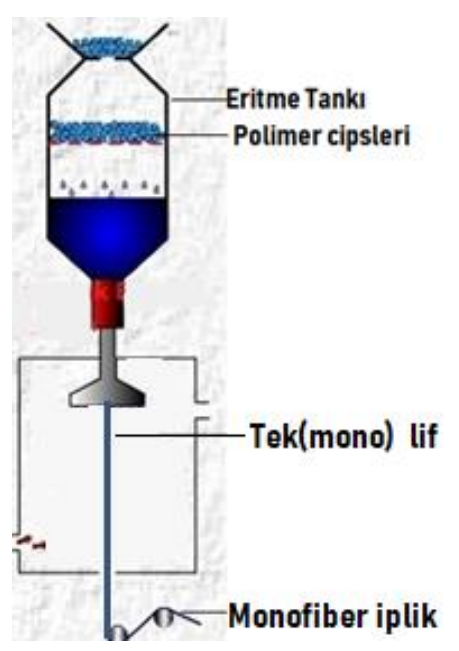


(b)

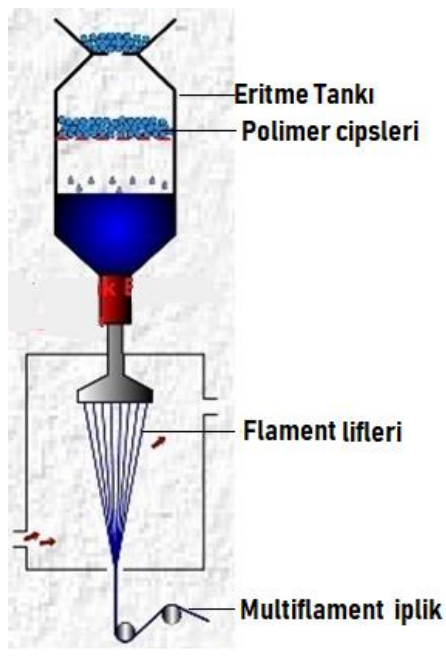

Şekil 5. (a) Tek lifli(monofiber) iplik üretim şeması ve (b) Çok lifli (multifilament) iplik üretim şeması

\subsection{Koagülasyon (Katılaşma)}

Düzelerde belirli bir sıcaklık ve basınçla püskürtülen polimer eriyiği katılaşacağı bir ortama iletilir. Katılaştırma işlemi çeşitli şekillerde yapılır. Bunlar; sıcak buhar, soğuk hava veya koagülasyon banyosu yöntemleridir. Düzelerden çok yüksek sıcaklıkta akarak çıkan sıvı kütlesi bu bölümde katılaşarak filament hâline getirilir. Bu sıvı kütlesinin katılaştırma işlemi, ipliğin kazanaca ğı mukavemet ve uzama özelliklerini kritik bir şekilde etkiler. Lifler soğumaya başladığında kristalizasyon hala yüksek olduğundan ve erime durumu da ortadan kalktığından, hızla yeni kristalitler oluşmaktadır. Lifler $125-130^{\circ} \mathrm{C}^{\prime}$ ye kadar soğuduktan sonra ise, kristalizasyon hızının iyice yavaşlaması nedeniyle, yeni kristalit oluşumu durmaktadır. Yani soğutma esnasında oluşan kristalitlerin sayısı ve kalitesi, lifler termofiksaj sıcaklığından $125-130^{\circ} C^{\prime}$ ye soğuyuncaya kadar geçen süreye bağlıdır[14]. Eriyikten lif çekimi lif çekimi ve sarılması esnasında erime sıcaklığı, camlaşma sıcaklığı ve yapısal elastikiyet gibi özelliklerin mutlaka hesaba katılması gerekmektedir. Sentetik liflerin sahip olduğu düşük erime sıcaklığı nedeniyle lif hattındaki filamentin soğutulma işlemine kadar çok kısa bir süre bulunmaktadır. Katılaştırma ve soğutma işlemleri sırasında lif morfolojisini önemli ölçüde geliştirmektedir[15].

\subsection{Germe Çekme İşlemi}

Poliester lifleri germe-çekme işleminden önce amorf yapıdadırlar. Bu liflerden kullanışlı dokuma liflerinin elde edilebilmesi için lifin hem moleküler oryantasyonu hem de kristalizasyonunu artıracak şekilde germe-çekme işlemlerinin yapılması gereklidir. Bu işlem camsı geçiş sıcaklığ 1 olan $80^{\circ} \mathrm{C}$ 'nin üzerinde yapılır. Çünkü camsı geçiş sıcaklığının altında çekilen polimer zincirleri birbiri üzerinden kolayca kayamadığından oryante olmaları oldukça zordur[10].

Monofilamentler 100 dtex’i aşan kalınlıkları ile multiflamentlerden çok daha kalındırlar. Multifilamentlerin üretildiği gibi üretilebilirler. Ancak bu şekilde üretilen monofilamentler kıvrımlılaşma eğilimi göstermektedir. Bu özelliği onların birçok alanda kullanımını sınırlamaktadır. Bu problemi aşabilmek için monofilamentler çoğu kez daha düşük hızlarda üretilirler ve daha etkili bir soğutmanın yapılabilmesi için su içerisine gönderilirler. Monofilament düzeden çıktıktan $5 \mathrm{~cm}$ kadar sonra bir su banyosuna girer. Soğutma işleminden sonra germe çekme işlemi yapılır. Germe-çekme sıcak su banyosu veya sıcak hava kanalında yapılabilir[16].

Çekim kısmı üç çift silindirden oluşur. Bu silindirler (çekim silindirleri)yüzeyi yivli ve dişlilerden gelen tahrikle dönen mil şeklindeki taşıyıcı silindirlerdir. Çekim sırasında elyafın kontrol altında tutulmasını sağlayan bu silindirler, üstünde birlikte çalışan bir baskı silindiriyle beraber kullanılırlar[17]. Bunların üzerinde basınç yapan pendeller vardır. Çekim aparatlarında 1. silindirin basıncı fazladır. 2. ve 3.silindirler daha çok kendi ağırlıklarıyla basınç yaparlar. Çekim; silindirlerin birbirinden daha hızlı dönmesiyle oluşur. Arkadaki silindirlerde çekim daha azdır. Çünkü burada fitildeki bükümün çözülmesi sağlanır. Esas çekim 2.ve 3. silindirler arasindadir[12].

\subsection{Yağlama ve Anti Statik İşlem}

Üretilen filamentler bobinlere sarılmadan önce spin-finish adı verilen bir yağ ile temas ettirilir. Spin-finish; yağlayıcı, statik elektriğgi dağıtıc1, 1slatıcı, kir itici, antimikrobiyel, oksitlenme giderici gibi bazı maddeleri içeren bir bitim işlemi olarak ele alınabilir. Bu sayede liflerin karışması, birbirine yapışması ve statik elektriklenme gibi bazı olumsuzluklar engellenmiş olur. Spin-finish içeriği üretilen liflere ve bunların karşılaşacağı işlemlere bağlı olarak hazırlanır[18].Sentetik liflerin pamuk gibi doğal liflerden farklı olarak elektrik iletkenlikleri çok düşüktür. Bundan dolayı statik elektriklemeye neden olur. Bunun sonucunda aşağıdaki sorunlar ortaya çıkmaktadır:

1. Çekim esnasında şeritteki lifler taşıdığı yüklere göre birbirini ya iter ya da çekerler ve bunun sonucunda çıkan şerit düzgünlüğ̈̈ kötüleşir.

2. Yüklü liflerin birbirini itmesi ya da çekmesi nedeniyle iplikteki lif düzeni bozulur ve iplik düzgünlüğü kötüleşir ve iplikteki hatalar artar.

3. Statik elektriklenme lif göçmesine neden olur. Çünkü iplik üretim süresince yüklü liflerin birbirini itmesi sebebiyle bir lif veya filament iplik eksenine göre yer değiştirecektir. 
Statik elektriklenmeyi ortadan kaldırmak amacıyla farklı isimlerle bilinen; harman yağı, anti stat, spinfinish ve yağlayıcı madde gibi özel yağlar kullanılmaktadır. Bu yağların kullanım oranları tekstil materyalinin harmandan son mamule kadar kalitesini etkileyen önemli bir faktördür[19].

\subsection{Polyester (Multifilament) İplikte Büküm İşlemi}

Polyester ham maddeden üretilen multifilament lifleri bir bütünlük kazandırarak iplik yapısı oluşturmada en çok bilinen yöntem, lif topluluğuna büküm uygulamaktır. Uygulanan büküm neticesinde, oluşan ipliğin mukavemet özelliklerinin yanı sıra; ipliğin çapı, aşınma direnci, eğilme rijitliği, tutumu, parlaklı̆̆ı vb. gibi pek çok özellik de etkilenir. Bükümün iplik yapılarındaki temel etkisi, ipliği oluşturan lifler üzerinde meydana gelen yanal kuvvetler vasıtasıyla olur. Bu sayede; iplik yapısını oluşturan lifler birbirine daha sıkı tutunur[20].

\section{Dokuma İşlemi}

Dokuma kumaşlar, çözgü ve atkı olarak adlandırılan birbirine dik iki iplik sisteminden oluşan tekstil yapılarıdır. Dokumada çözgü iplikleri birbirine paralel olarak belli bir sayıda ve yan yana bulunur. Dokumanın yapıldığı yöne doğru ilerlemesi gereken çözgü tabakası arasından atkı ipliğinin geçirilmesi ve bunun dokumaya dâhil edilmesi sürekli olarak tekrarlanan temel işlemlerdir[21]. Atkı ve çözgü iplik sıklıkları, dokuma kumasın gözenek boyutlarını doğrudan etkileyen parametrelerdir. S1klık değerleri arttıkça, gözenek boyutları azalır. İçerisinden akışkanın geçmesine daha fazla direnç gösterir, akışkanın hızı azalır. Örgü türü, , atkı sıklığı, çözgü sıklığı, lif kesit yapısı değerleri serigrafi baskı işleminde dokumanın boya geçirgenliğini belirleyen önemli parametrelerdir[22].

(b)

\section{(a)}
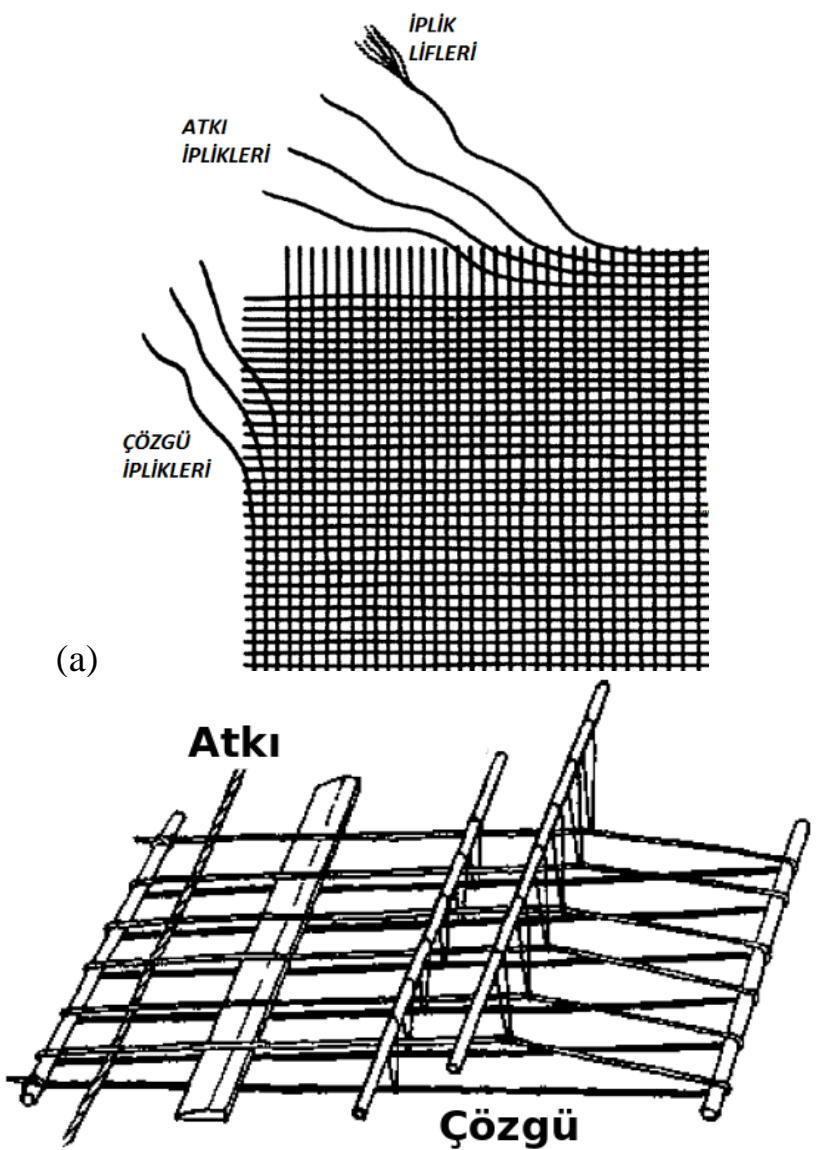

Sekil 6. (a) Dokumayı meydana getiren çözgü ve (b) atkı iplikleri

Serigrafi baskı işleminde kullanılan sentetik dokumalar, iki iplik sisteminin birbiriyle $90^{\circ}$ 'lik açı yapacak şekilde, dokuma örgülerine göre birleştirilmesiyle oluşur. Bu dokuma türüne 'bez ayağı dokuma' denilmektedir. Çözgü iplikleri belirli sayıda ve birbirlerine paralel halde bulunur. 


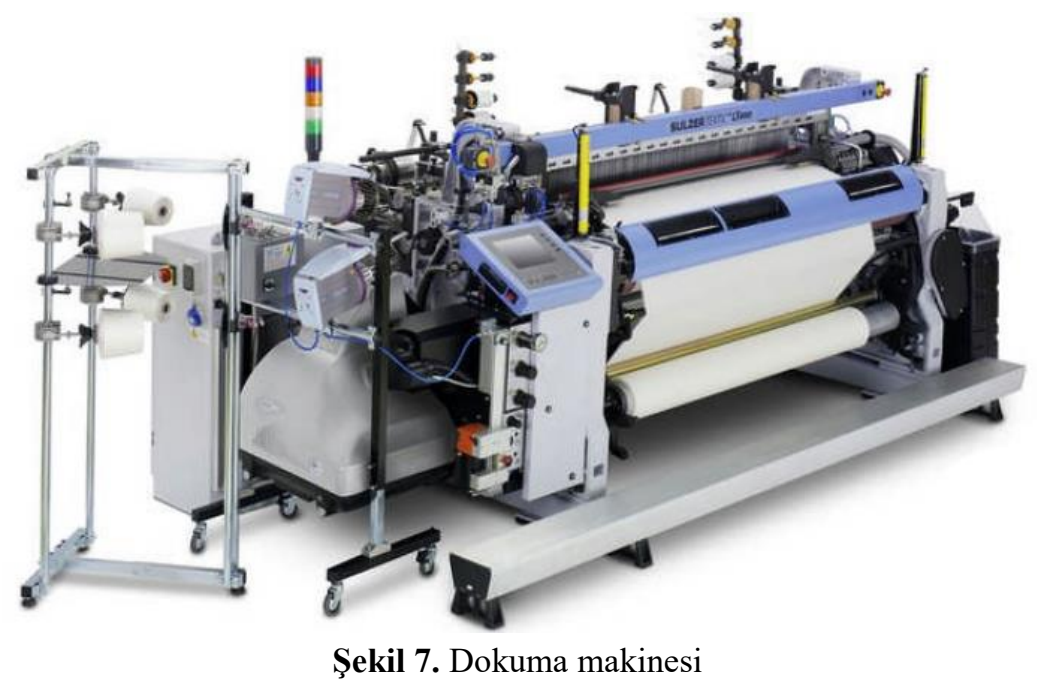

(a)
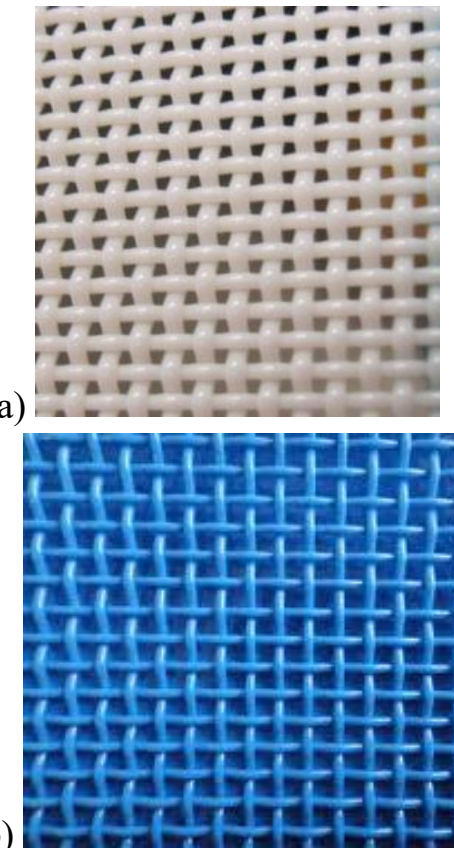

Şekil 8. (a) Polyester multifilament dokuma ve (b) Polyamidmonofilament dokuma

\section{5. Üretim Prosesinde Baskı Kalitesi ve Kullanım Performansını Belirleyen Parametreler}

\subsection{Ham Madde aşamasında Sonucu Etkileyen Unsurlar}

- Polimerin saf olmasının sağlanması (yüksek derecede filtrasyon)

- Polimer viskozitesinin uygun hale getirilmesi (yüksek çekim sıcaklığı viskoziteyi azaltmaktadır)

\section{2. İplik Üretim Aşamasında Sonucu Etkileyen Unsurlar}

- Düzenin her meme deliğinin eşit miktarda beslenmesi

- Düze altındaki ortam sıcaklığının uygun hale getirilmesi (soğutma hızının kontrol edilmesi)

- Filamentlerin aynı soğutma koşulu altında katılaşması sağlanmalıdır

- Filamentlerin bir araya getirilmesinin uygun şekilde yapılması (düzeye en yakın yerde bir araya getirme)

- Lif çekiminin uygun hale getirilmesi (eğirme geriliminin kontrol edilmesi)

- Düşük hızda çekim (düzgün polimer iletimi)

\subsection{Dokuma Așamasında Sonucu Etkileyen Unsurlar}

- CÇözgüve atkı kaçı̆̆ı oluşumları

- Çift atkı veya çift çözgü oluşumları

- Gergin veya gevşek çözgü

- İ̀ düzgünsüzlügüü[23]. 


\section{Sonuç}

Serigrafi baskı kalıbı olarak kullanılan sentetik dokumalar son aşamaya gelinceye kadar birçok işlemden geçmektedir. Bu işlemlerin bazıları ürünün sonucunu fazla etkilemezken bazı işlemler sonucun kalitesinde belirleyici olabilmektedir. Makalede serigrafi baskı tekniğinde kalıp malzemesi olarak kullanılan polyamid ve polyester sentetik dokumaların baskı kalitesini ve kullanım performansını belirleyen üretim unsurları analiz edilmiştir. Analiz, süreç bazlı olarak üretim işlem sırasına göre yapılandırılmıştır. Sentetik dokumanın üretim süreci, hammaddenin hazırlanmasından başlayarak dokumanın satışa hazır hale gelene kadar üç bölümden meydana gelmektedir. Her bölüm kendine özgü girdileri, çıktıları ve işlemleri vardır. Her bölümünün kendine ait sonucu etkileyen parametreleri vardır. Diğer endüstriyel üretim proseslerinde olduğu gibi sentetik dokuma üretim prosesi ilk işlem süreci üretimin son aşamasına kadar sonucu belirlediği gibi kullanım performansını da belirleyen bir bütünsel yapı durumu oluşturmaktadır. Bu nedenle proseslerin hepsi aynı önem değeri ile en üst uygunlukta gerçekleştirilmeye çalışması gerekmektedir. Hatalı üretilen bir dokumanın kullanıldığı serigrafi baskı işleminde ne kadar özenli çalışma ortaya konulsa da dokumadan kaynaklanan problem baskı sonucunu etkilemesi kaçınılmaz olacaktır.

Baskı işleminde çok iyi şablon kalıp oluşumunu sağlamak, baskı işleminde mürekkebin baskı altı malzemeye ideal biçimde transferini sağlamak, dokumayı daha uzun süre verimli bir şekilde kullanmak, tüm unsurları ile istenen değerlerde üretilmesi ile sağlanabilecektir.

İyi bir dokuma ile vasat bir dokuma arasında baskı sonucu açısından belirgin farkların olması kaçınılmaz bir durum olarak karşımıza çıkmaktadır. Serigrafi baskı operatörü bu farkı uygulamalı olarak test ettiğinde sorunlu dokumayı tercih etmemektedir. Ya da ekonomik gerekçelerden dolayı sadece kalitesi düşük baskı işlemlerinde kullanma yoluna gitmektedir. Bazen iyi dokuma olarak satın alınan bobinde sorunlu kısımlarla karşılaşılmaktadır. Bunun sebebi yukarıda belirtilen unsurların bir ya da birkaçında stabil olması gereken değerlerin korunamamasından kaynaklanabilmektedir.

Bu makale, "Serigrafi Baskıda Fotomekanik Yöntemler” yüksek lisans tezimden türetilmiştir.

\section{Kaynakça}

[1] T. Şahinbaşkan, "Kumaş Baskısında Serigrafi Baskı Elek Sıklığının ve Rakle Açısının Tram Nokta Yapısına Etkisinin İncelenmesi”, Politeknik Dergisi Journal of Polytechnic, c. 12, s. 3, ss. 138, 2009.

[2] M. Saçak, Polimer Kimyasına Giriş, Ankara, Türkiye: A. Ü. F. F. Yayınları, 1998, No. 50.

[3] B. Beşergil, Polimer Kimyası, Ankara, Türkiye: Gazi Kitabevi, 2008, ss. 31.

[4] E. Erdem ve İ. Morgit, "Lise Öğrencilerinin Temel Polimer Bilgileri Üzerine Bir Çalışma”, Hacettepe Üniversitesi Eğitim Fakültesi Dergisi, s. 23, ss. 88, 2002.

[5] J. Rivlin, The Dyeing of Textile Fibres - Theory and Practice, Philadelphia, A.B.D: 1992, ss. 170-175.

[6] D. Yılmazer ve M. Kanık, "Poliamid Liflerinde Meydana Gelen Kimyasal Hasarın Tespiti”, Uludağ Üniversitesi MühendislikMimarlık Fakültesi Dergisi, c. 14, s. 2, ss. 199, 2009.

[7] P. Kayadibi, "Dar dokuma kumaş yapıları ve üretimi”, Fen Bilimleri Enstitüsü, Gazi Üniversitesi, Ankara, Türkiye, 2013.

[8] E. Bayraml, "Kompozit Polimerler”, Bilim ve Teknik, Şubat, s. 38, 1995.

[9] Anonim, [Online]. Erişim: 10 Ağustos 2018, http://www.megep.meb.gov.tr/mte_program_modul/moduller/Yapay\%20lifler.pdf

[10] A. Demir, Sentetik Filament İplik Üretim ve Tekstüre Teknolojileri, 1. Bask1, İstanbul, Türkiye: Şan Ofset, 2006.

[11] N. Erdem, Kimyasal Lifler, Ders Notları, İzmir, 2009.

[12] Ş. Kara, "Farklı enine kesit şekillerinde üretilen kimyasal liflerin yapısal davranışları ve kullanım özelliklerinin incelenmesi", Yüksek lisans tezi, Fen Bilimleri Enstitüsü, Dokuz Eylül Üniversitesi, İzmir, Türkiye, 2011.

[13] A. Ilıman, "Polyester Devamlı Lif ve Kesik Elyaf Üretim Sistemleri ve Özellikleri”, Seminer Notları, Tubitak-MAM/SAGEM Tekstil Enstitüsü, 1998.

[14] S. Çirkin, "Yalancı büküm tekstüre işleminde tekstüre değişikliklerinin iplik özellikleri üzerindeki etkisi”, Yüksek lisans tezi, Fen Bilimleri Enstitüsü, Çukurova Üniversitesi, Adana, Türkiye, 2006.

[15] F. F. Yıldırım, O. Avinç ve A. Yavaş, "Poli (trimetilen Tereftalat) Lifleri Bölüm 1: Üretimi, Özellikleri, Kullanım Alanları, Çevresel Etkisi”, Tekstil ve Mühendis, c. 19, s. 87, ss. 44, 2012.

[16] J. E. Mclntyre, Synthetic fibers: Nylon, polyester, acrylic, polyolefin, 1. Bask1, Cambridge, İngiltere: Woodhead Publishing Limited, 2005.

[17] M. Yakartepe ve Z. Yakartepe, Tekstil Teknolojisi Elyaf’tan Kumaş'a, İstanbul, Türkiye: T.K.A.M. Yayınları, 1995, c. 2.

[18] C.B. Chapman, Fibres, 1. Bask1, Londra: İngiltere: Textile Book Service Press, 1974.

[19] K.Alhalabi ve E.C. Sabır, “Anti Statik Yağın İplik Kalite Parametrelerine Etkisi”, Ç.Ü. Müh. Mim. Fak. Dergisi, s. 26(2), ss.1932, 2011.

[20] S. Ömeroğlu, E. Karaca, B. Becerir ve E.B. Akbaş, "Poliester İpliklerde Kesit Büküm Mukavemet İlişkisi”, Uludağ Üniversitesi Mühendislik-Mimarlık Fakültesi Dergisi, c. 16, s. 2, ss. 46, 2011.

[21] M. Akgün, H.R. Alpay ve B. Becerir, "Kumaş Yapılarındaki İpliklerin Reflektans Değişimlerinin İncelenmesi”, Uludağ Üniversitesi Mühendislik-Mimarlık Fakültesi Dergisi, c. 17, s. 2, ss. 92, 2012.

[22] F.M. Şenol ve E. Türker, "Polyester Dokuma Kumaşların Su Geçirgenliğine Etki Eden Faktörlerin İncelenmesi”, Tekstil ve Konfeksiyon Dergisi, s. 2, ss.118, 2009.

[23] T. Nakajima, Advanced Fiber Spinning Technology, İngiltere: Woodhead Publishing Limited, s.38, 1994. 